\title{
Environmental and sociodemographic factors associated with household malaria burden in the Congo
}

\author{
Nlandu Roger Ngatu ${ }^{*}$ (D), Sakiko Kanbara ${ }^{2}$, Andre Renzaho ${ }^{3}$, Roger Wumba ${ }^{4}$ Etongola P. Mbelambela ${ }^{5}$, \\ Sifa M. J. Muchanga ${ }^{6}$, Basilua Andre Muzembo ${ }^{1}$, Ngombe Leon-Kabamba7 , Choomplang Nattadech', \\ Tomoko Suzuki ${ }^{1}$, Numbi Oscar-Luboya ${ }^{8}$, Koji Wada ${ }^{1}$, Mitsunori Ikeda², Sayumi Nojima ${ }^{2}$, Tomohiko Sugishita ${ }^{9}$ \\ and Shunya Ikeda'
}

\begin{abstract}
Background: Malaria is one of the most severe public health issues that result in massive morbidity and mortality in most countries of the sub-Saharan Africa (SSA). This study aimed to determine the scope of household, accessibility to malaria care and factors associated with household malaria in the Democratic Republic of Congo (DRC).

Methods: This was a community-based cross-sectional study conducted in an urban and a rural sites in which 152 households participated, including 82 urban and 70 rural households (1029 members in total). The 'malaria indicator questionnaire' (MIQ) was anonymously answered by household heads (respondents), reporting on malaria status of household members in the last 12 months.

Results: There were $67.8 \%$ of households using insecticide-treated bed nets (ITN) only, 14.0\% used indoor residual spraying (IRS) only, 7.3\% used ordinary bed nets (without insecticide treatment), 1.4\% used mosquito repelling cream, $2.2 \%$ combined ITN and IRS, whereas $7.3 \%$ of households did not employ any preventive measure; $p<0.01$ ). In addition, $96.7 \%$ of households were affected by malaria (at least one malaria case), and malaria frequency per household was relatively high (mean: $4.5 \pm 3.1$ cases reported) in the last 12 months. The mean individual malaria care expenditure was relatively high (101.6 \pm 10.6 USD) in the previous 12 months; however, the majority of households (74.5\%) earned less than 50 USD monthly. In addition, of the responders who suffered from malaria, 24.1\% did not have access to malaria care at a health setting. Furthermore, a multivariate analysis with adjustment for age, education level and occupation showed that household size $(\mathrm{OR}=1.43 \pm 0.13 ; 95 \% \mathrm{Cl} 1.18-1.73 ; \mathrm{p}<0.001)$, inappropriate water source $(\mathrm{OR}=2.41 \pm 0.18 ; 95 \% \mathrm{Cl} 1.17-2.96 ; \mathrm{p}<0.05)$ absence of periodic water, sanitation and hygiene (WASH) intervention in residential area $(\mathrm{OR}=1.63 \pm 1.15 ; 95 \% \mathrm{Cl} 1.10-2.54 ; \mathrm{p}<0.05)$, and rural residence $(\mathrm{OR}=4.52 \pm 2.47 ; 95 \% \mathrm{Cl} 1.54-13.21$; $p<0.01$ ) were associated with household malaria.
\end{abstract}

Conclusion: This study showed that household size, income, WASH status and rural site were malaria-associated factors. Scaling up malaria prevention through improving WASH status in the residential environment may contribute to reducing the disease burden.

Keywords: Environment, Household malaria, Income, Sanitation

\footnotetext{
*Correspondence: doc.rogerngatu@gmail.com

1 School of Medicine and Graduate School of Public Health, International

University of Health and Welfare, Narita, Japan

Full list of author information is available at the end of the article
}

(c) The Author(s) 2019. This article is distributed under the terms of the Creative Commons Attribution 4.0 International License (http://creativecommons.org/licenses/by/4.0/), which permits unrestricted use, distribution, and reproduction in any medium, provided you give appropriate credit to the original author(s) and the source, provide a link to the Creative Commons license, and indicate if changes were made. The Creative Commons Public Domain Dedication waiver (http://creativecommons.org/ publicdomain/zero/1.0/) applies to the data made available in this article, unless otherwise stated. 


\section{Background}

Recent reports from the World Health Organization (WHO) show progress made by several countries in reducing malaria burden, with a decline in preventable child deaths over the 15-year period of the implementation of millennium development goals (MDGs). Epidemiologic figures show that over 6.2 million malaria deaths were averted between 2000 and 2015 in subSaharan Africa (SSA) [1]. Malaria is an infectious disease that continues to pose a major health challenge; it is still endemic in 97 countries, including the Democratic Republic of Congo (DRC) where only $56 \%$ of children under age five sleep under insecticide-treated bed nets [2-4]. In several malaria-affected countries, scale-up interventions are being implemented to reduce the disease burden, such as long-lasting insecticide-treated nets (LLIN), indoor residual spraying (IRS), rapid diagnostic tests (RDT) and artemisininbased combination treatment (ACT).

Despite the progress made in the fight against malaria, a number of challenges are currently reducing the impact of antimalarial interventions such as the emergence of drug-resistant malaria parasites and mosquitoes resistant to insecticides, and the existence of fake malaria drugs $[3,5,6]$. Furthermore, many of high malaria burden countries such as Nigeria and DRC have been reporting significant increases in disease cases [4], suggesting the necessity for further research that could culminate in the discovery of new strategies for malaria control.

Primary health care (PHC) system has been playing a crucial role in reducing malaria burden in endemic countries, and such an achievement can only be reached if adequate infrastructure, delivery mechanisms and uptake for PHC coverage are available, in addition to minimum acceptable income. Moreover, in the context of malaria endemic countries, there is still a need to make malaria preventive and curative treatments not only available but also accessible [7-9]. In $\mathrm{DRC}$, given extreme poverty and the dysfunction of the national health system due to cyclic armed conflicts, insecurity and governance issues, universal health coverage (UHC) remains a dream. In DRC, poverty-related inaccessibility to health care has caused increased rates of self-medication and use of herbal medicines $[10,11]$.

This first 'Congo Malaria and Environment study' was conducted to determine the frequency of malaria in households, malaria care accessibility and factors associated with household malaria, as well as the impact of water, sanitation, hygiene (WASH) status and income on disease burden.

\section{Methods}

\section{Study design, sites and participants}

This was an observational community-based crosssectional study conducted in two sites located in two different provinces: Kasangulu, a rural town in Kongo central province, and Limete, an urban county located in the capital Kinshasa. Invitations were sent to two communities in each study sites to join this survey and 181 survey sheets were distributed, of which 152 were completed. Thus, this study sample was 152 households (82 from urban and 70 from rural study sites), consisting of 1029 individuals. Home visits were carried out for to evaluate WASH status, the quality of malaria prevention tools used by households.

Participation was voluntary, and heads of households were enrolled in their respective communities (cultural or social centre, club and church) after attending meetings in which a thorough explanation about the survey was delivered. Each participating community provided a codified list of volunteer participants. The same codes were transcribed on questionnaire sheets that were later distributed to participants.

\section{Survey questionnaire}

The 'Malaria Indicator Questionnaire (MIQ) [12, 13], a standardized structured and self-administered survey questionnaire, was used in this study. MIQ is a composite questionnaire that comprises items that correspond to five main themes, including personal and household sociodemographic and clinical characteristics of respondents (household heads) at the time of this survey, lifestyle pattern, personal and family medical history, and information on WASH status at home and in the living environment, and malaria preventive measures and care options. It is a survey questionnaire from 'The World Bank and WHO Malaria Programme' in Africa, commonly used by many western and eastern African countries to evaluate their respective malaria programmes. Considering the relatively high illiteracy rate in the country, the questionnaire was self-administered for educated respondents; whereas, for illiterate respondents, the team of surveyors (which included trained community health nurses and a medical doctor) explained each question in a local dialect and guided them.

\section{Study outcome variables}

For this study, the outcomes were household malaria incidence (number of incident cases) in the previous 12 months, and accessibility to malaria care at a medical settings. 


\section{Ethical considerations and data analysis}

Ethical approvals of the study were obtained from the ethics committee of the Graduate School of Nursing, University of Kochi, Japan, and the School of Public Health of the University of Lubumbashi, DRC. Signed written informed consent was obtained from each household head.

For data analysis, Stata statistical software version 14 (Stata Corp.; TX, US) was employed. Differences between categories of qualitative variables (study site, sociodemographic characteristics, preventive measures, and place of malaria care) and dichotomized variables (WASH parameters, range of household malaria cases, and household income status) were assessed with the use of Chi square test. The breakdown of WASH components was performed as follows:

1. Household latrine (toilet): appropriate (pit latrine with slab and flush; pit latrine with slab and manual flush) or inappropriate (pit latrine without slab);

2. Household water source: appropriate (indoor tap water) or inappropriate (outdoor tap water or water well).

Variables that showed significant and marginally significant associations with household malaria in the bivariate model were entered into the multivariate logistic regression model to determine the factors associated with malaria. P-values (double sided) less than 0.05 were considered significant.

\section{Results}

\section{Characteristics of the households and the respondents}

Of the 181 survey questionnaires distributed to household heads (responders), 152 (83.9\%) were returned; $51.3 \%$ of respondents were males and $48.7 \%$ females. Of the responders, $40.2 \%$ were aged 30 to 39 years, and $65.1 \%$ were married. Additionally, the majority (78.3\%) of respondents were unemployed. Regarding educational level of the respondents, a greater proportion (41.5\%) had high school level (Table 1). On one hand, the majority (54\%) of households were from urban area, had a larger size (53.3\%; range: 6-18 members), had a monthly income less than 50 USD (75\%), used either water well or outdoor tap water $(58.3 \%)$, and used pit latrine without slab (uncovered toilet, 78.2\%); on the other hand, $37.5 \%$ of households shared latrines with neighbors, $82.9 \%$ owned a radio, but only $58.6 \%$ owned a television (TV) set as shown in Table 1.

Trend of household malaria frequency in the last 12 months according to study site, preventive measures used and income status. As shown in Fig. 1, a relatively
Table 1 Characteristics of respondents and households

\begin{tabular}{|c|c|c|}
\hline Characteristics & $\mathbf{N}$ & $\%$ \\
\hline \multicolumn{3}{|c|}{ (1) Respondents (household heads; $n=152$ ) } \\
\hline \multicolumn{3}{|l|}{ Gender } \\
\hline Male & 78 & 51.3 \\
\hline Female & 74 & 48.7 \\
\hline \multicolumn{3}{|l|}{ Age (years) } \\
\hline $20-29$ & 24 & 15.8 \\
\hline $30-39$ & 61 & 40.2 \\
\hline $40-49$ & 37 & 24.3 \\
\hline $50-70$ & 30 & 19.7 \\
\hline \multicolumn{3}{|l|}{ Marital status } \\
\hline Married & 99 & 65.1 \\
\hline Divorced & 6 & 4.0 \\
\hline Widowed & 8 & 5.2 \\
\hline Single with children & 22 & 14.5 \\
\hline Single without children & 17 & 11.2 \\
\hline \multicolumn{3}{|l|}{ Education } \\
\hline Never gone to school & 11 & 7.2 \\
\hline Primary & 8 & 5.3 \\
\hline High school & 63 & 41.5 \\
\hline Technical school & 25 & 16.4 \\
\hline University/College & 45 & 29.6 \\
\hline \multicolumn{3}{|l|}{ Occupation } \\
\hline Unemployed & 119 & 78.3 \\
\hline Employed & 33 & 21.7 \\
\hline \multicolumn{3}{|c|}{ (2) Households (total members: $n=1029$ ) } \\
\hline \multicolumn{3}{|l|}{ Family/household size } \\
\hline $2-5$ & 71 & 46.7 \\
\hline $6-18$ & 81 & 53.3 \\
\hline \multicolumn{3}{|c|}{ Households with children $<5$ years } \\
\hline No & 45 & 29.6 \\
\hline Yes & 107 & 70.4 \\
\hline \multicolumn{3}{|l|}{ Residential area } \\
\hline Rural & 70 & 46.0 \\
\hline Urban & 82 & 54.0 \\
\hline \multicolumn{3}{|l|}{ Monthly income status } \\
\hline Overall less than 50 USD & 114 & 75 \\
\hline 50 USD or more & 38 & 25 \\
\hline Rural less than 50 USD & 62 & 88.6 \\
\hline 50 USD or more & 8 & 11.4 \\
\hline Urban Less than 50 USD & 48 & 58.5 \\
\hline 50 USD or more & 34 & 41.5 \\
\hline \multicolumn{3}{|l|}{ Access to electricity } \\
\hline Yes & 134 & 88.2 \\
\hline No & 12 & 7.9 \\
\hline No answer & 6 & 3.9 \\
\hline \multicolumn{3}{|c|}{ Use of means of communication } \\
\hline Television (yes) & 89 & 58.6 \\
\hline Radio (yes) & 126 & 82.9 \\
\hline Telephone (yes) & 133 & 87.5 \\
\hline
\end{tabular}


Table 1 (continued)

\begin{tabular}{lrr}
\hline Characteristics & N & $\%$ \\
\hline Type of toilet used ( $n=147)$ & & \\
Pit latrine with slab and flush & 10 & 6.8 \\
Pit latrine with slab/manual flush & 22 & 14.9 \\
Pit latrine without slab & 115 & 78.2 \\
Shared latrine with neighbors ( $=152)$ & & \\
Yes & 88 & 57.9 \\
No & 57 & 37.5 \\
Other & 7 & 4.6 \\
Water source ( $n=151)$ & & \\
Indoor tap water (yes) & 63 & 41.7 \\
Outdoor tap water or water well (yes) & 88 & 58.3 \\
\hline
\end{tabular}

USD United States' dollar

higher proportion $(53.9 \%)$ of households were from the rural study site (vs. $46.1 \%$ from urban site; $\mathrm{p}>0.05$ ) (Fig. 1a). The overall proportion of malaria-affected households (at least one malaria case) was high $(96.7 \%)$ in the last 12 months (Fig. 1b); a relatively higher proportion of rural households reported a higher malaria frequency (6 cases or more) in the last 12 months, as compared with urban households (31.7\% vs. $17.6 \%$; $p>0.05$ ), but not significantly (Fig. 1c).

The rate of use of insecticide-treated bed nets (ITN) among participating households was also assessed, and it was observed that the majority of households (67.8\%) used ITN. Of the remaining 32.2\%, 14.0\% used indoor residual spraying (IRS), 2.2\% combined ITN and IRS, $7.3 \%$ used ordinary bed nets (without insecticide), and $1.4 \%$ used mosquito repelling cream $(\mathrm{p}<0.01)$ (Fig. 2a). In addition, no significant difference was observed when comparing the proportion of malaria-affected ITN users with ITN non-users (Fig. 2b). Regarding monthly income status, a higher (74.5\%) proportion of households earned less than 50 USD (vs. 25.5\% earning 50-700 USD; $\mathrm{p}<0.001$ ), and malaria occurred more frequently in households earning less than 50 USD as compared with those earning more $(\mathrm{p}<0.01)$ (Fig. 3).

\section{Trend of household malaria frequency in the previous 12 months according to sanitation (WASH) status in the residential area}

Mean number of household malaria cases reported by the respondents was relatively high, $4.5 \pm 3.1$. Figure 3 shows the status of water, sanitation and hygiene (WASH) in the living environment. It was observed that a significantly higher (78.2\%) proportion of households used inappropriate latrines (vs. 21.8\% using appropriate latrines; $\mathrm{p}<0.001$ ) (Fig. 4a); and a significantly higher proportion of households using inappropriate latrine (40.7\%) had a high malaria frequency (6 cases or more) in the last 12 months (vs. 25.3\% of household using appropriate latrine; $\mathrm{p}<0.01$ ) (Fig. 4b). Additionally, there were $58.3 \%$ of households used inappropriate water source (vs. 41.7\% for households using appropriate one) (Fig. 4c); however, no significant difference in malaria rate was

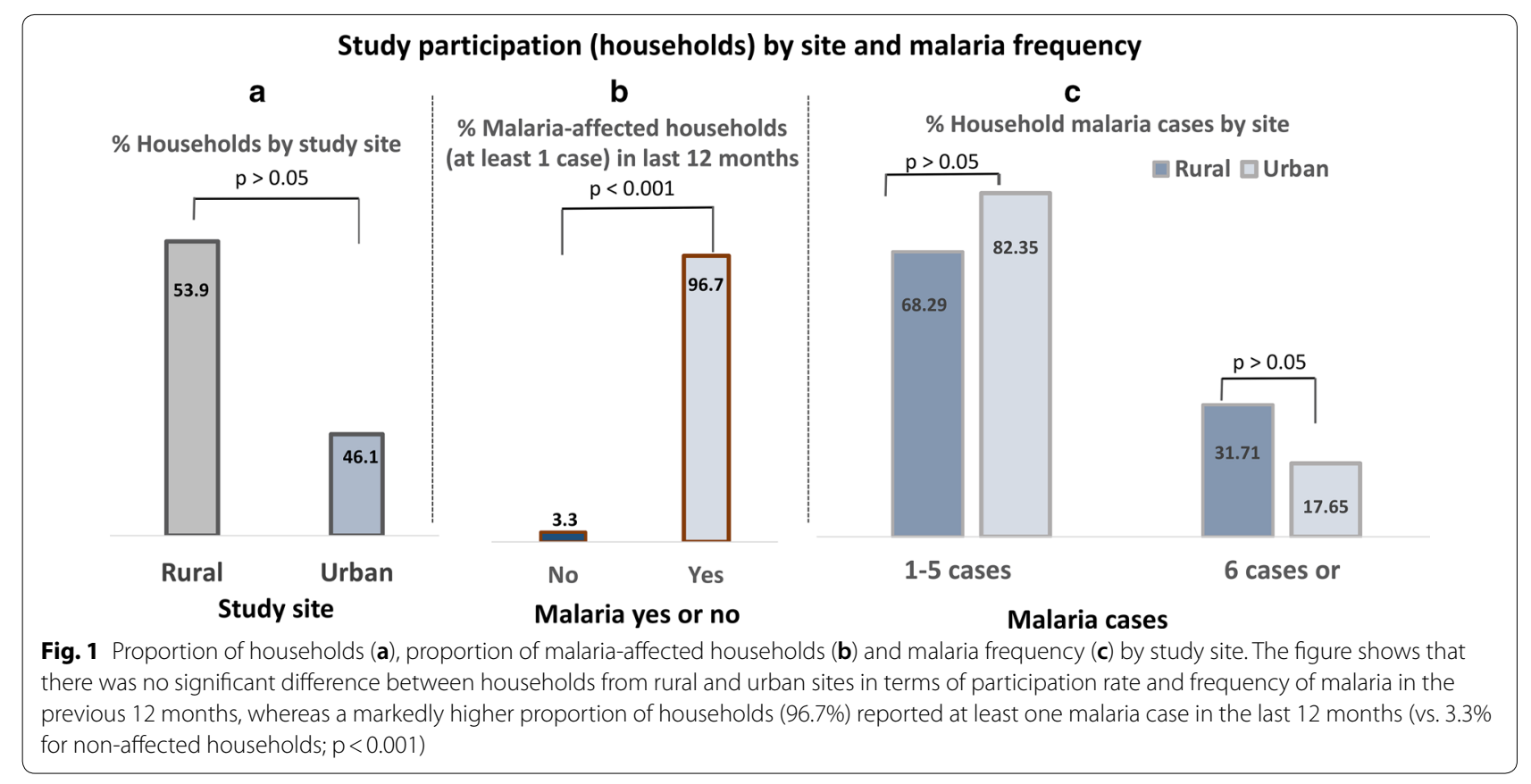




\section{Household use of preventive measures and malaria frequency}

a Use of insecticide-treated bednet (ITN) vs. other preventive measures

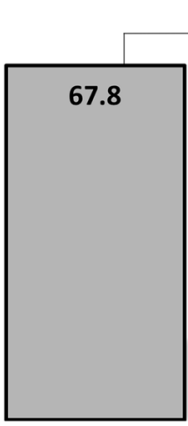

ITN use $p<0.01$

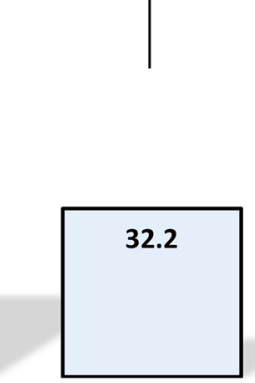

Other measure

\section{Malaria preventive measures}

Fig. 2 Household use of preventive measures (a) and malaria frequency (b). The figure shows that the majority of households owned insecticide-treated bed net (ITN); however, malaria frequency was not significantly different among households when considering the use of preventive measures (ITN users vs. ITN non-users). ITN: insecticide-treated bed nets; $p$, p-value

\section{Household income status and malaria frequency}

a

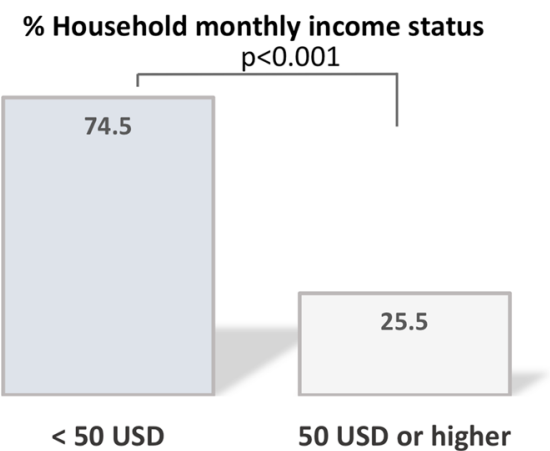

b

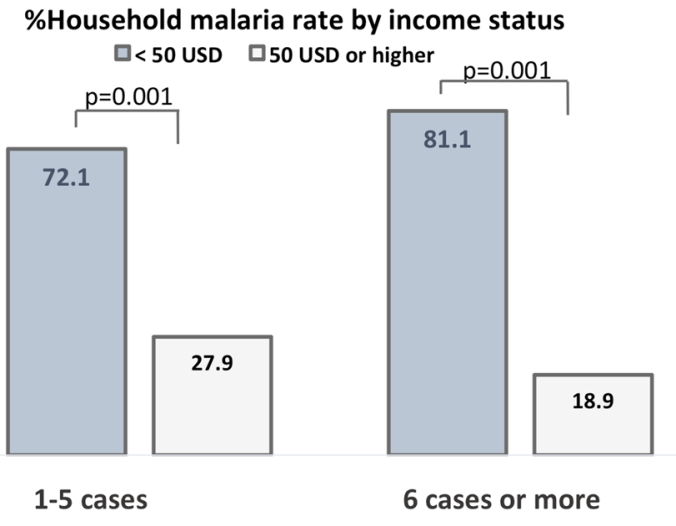

Fig. 3 Household income status (a) and malaria frequency (b). The figure shows that a higher proportion of households earning less than 50 USD monthly (a), and that poorer households tended to have higher frequency of malaria (b). USD: American dollar; p: p-value

observed when comparing households in term of quality of water source (Fig. 4d).

Furthermore, regarding the sanitation actions in the living environment, a higher $(83.8 \%)$ proportion of respondents reported the absence of implementation of periodic WASH intervention in their residential area (vs. $16.2 \%$ of those reporting such an intervention; $\mathrm{p}<0.0001$ ) (Fig. 4e). Consequently, households living in areas without WASH action were more likely to report malaria cases (vs. households from areas with periodic WASH intervention; $\mathrm{p}<0.001$ ) (Fig. 4f).

\section{Malaria care accessibility and settings for infected respondents}

In this study, 90.1\% (137/152) of the respondents who reported having developed at least one malaria episode in the previous 12 months were asked to mention whether malaria care was provided at a health setting (hospital, health centre or dispensary) or whether they opted for self-medication. Of them, $75.8 \%$ were taken care at a health setting, and the remaining $24.1 \%$ opted either for self-medication $(17.8 \%)$ or the use of 


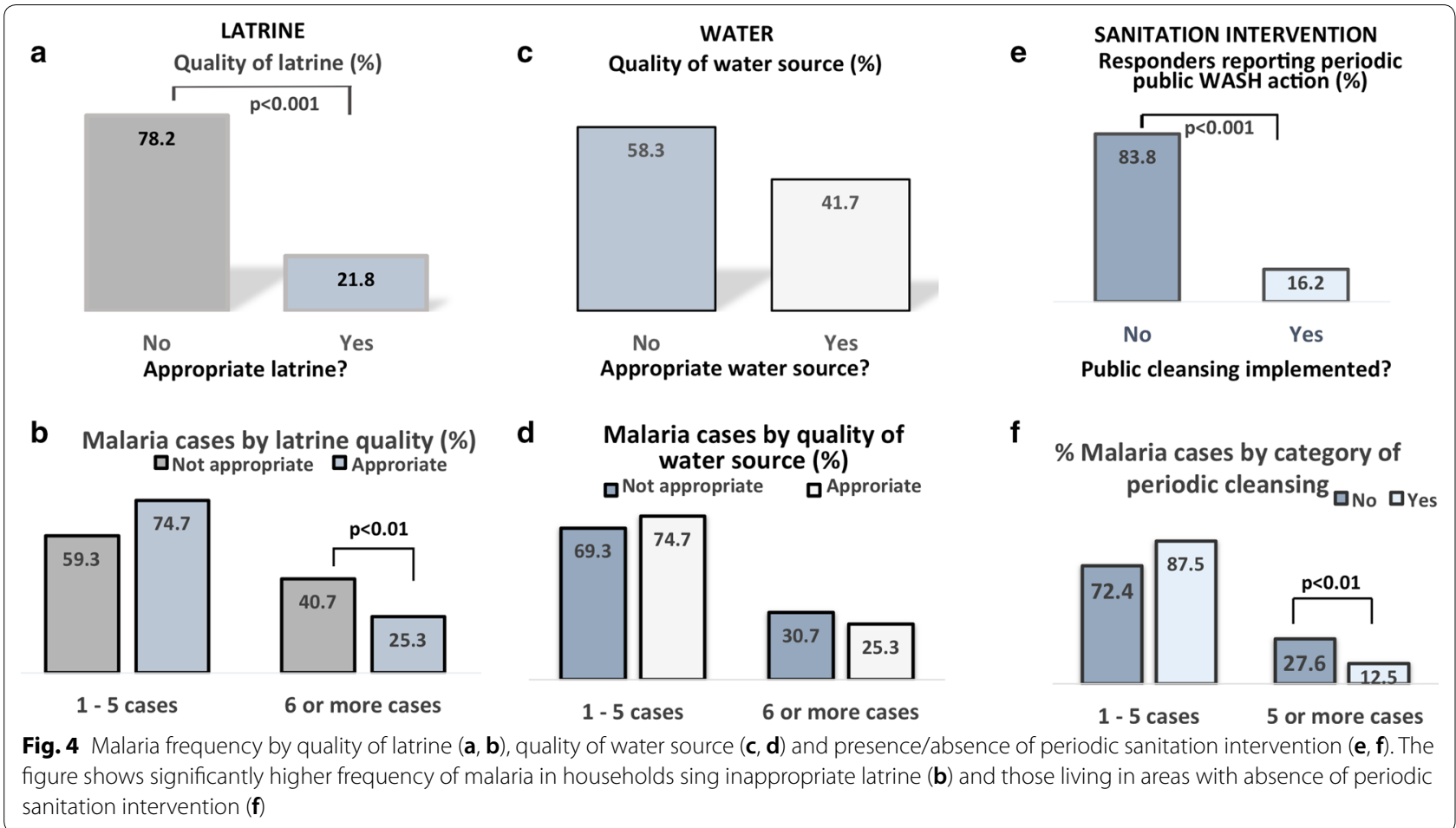

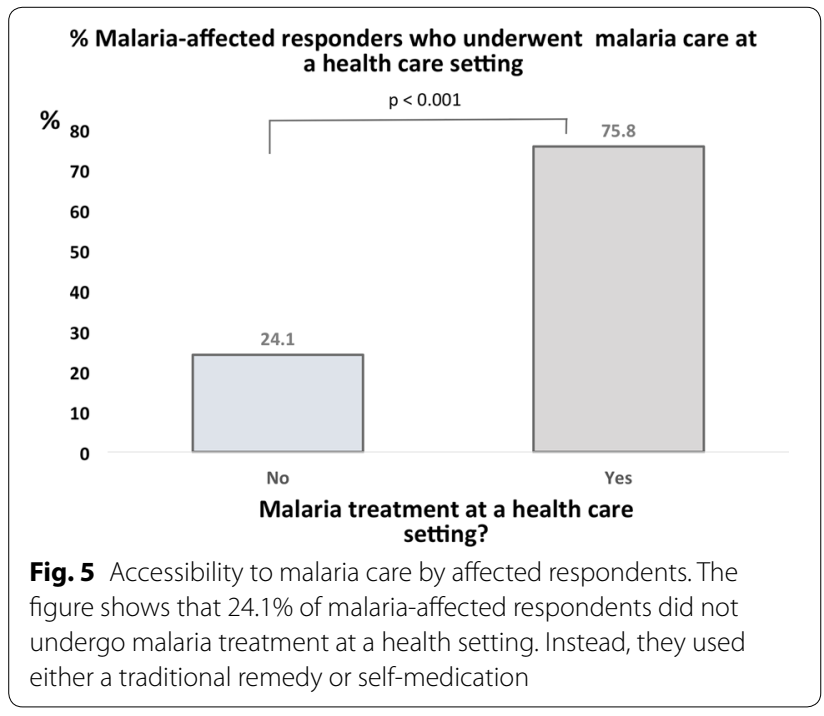

a traditional malaria therapy (6.3\%) after getting tested positive for malaria at a local health setting (Fig. 5).

\section{Association between household sociodemographic characteristics, WASH status and household malaria by logistic regression analysis}

A bivariate and multivariate logistic regression analyses were performed to determine factors associated with household malaria. In the bivariate analysis, the following factors were significantly associated with household malaria: household size $(\mathrm{OR}=1.30 \pm 0.08$; 95\% CI 1.14-1.49; $\mathrm{p}<0.001)$, low household income $(\mathrm{OR}=1.71 \pm 0.28 ; 95 \% \mathrm{CI} 1.23-3.51 ; \mathrm{p}<0.05)$, and periodic WASH intervention $(\mathrm{OR}=1.86 \pm 0.23 ; 95 \% \mathrm{CI}$ $0.10-1.26 ; \mathrm{p}<0.05)$. After adjusting for education, age and occupation, the multivariate analysis showed that household size $(\mathrm{OR}=1.43 \pm 0.13 ; 95 \%$ CI $1.18-1.73$; $\mathrm{p}<0.001)$, inappropriate water source $(\mathrm{OR}=2.41 \pm 0.18$; 95\% CI 1.17-2.96; $\mathrm{p}<0.05)$, periodic WASH intervention $(\mathrm{OR}=1.63 \pm 1.15 ; 95 \% \mathrm{CI} 1.10-2.54 ; \mathrm{p}<0.05)$, and rural residence $(\mathrm{OR}=4.52 \pm 2.47 ; 95 \% \mathrm{CI} 1.54-13.21 ; \mathrm{p}<0.01)$ were significantly associated with household malaria. No significant association was observed between household malaria, ITN use, and type of toilet, as shown in Table 2.

\section{Discussion}

The present study aimed to determine factors associated with malaria on household level in a sample of 152 Congolese households (1029 household members) from two counties (one in the capital Kinshasa and another one in the rural area of Kongo Central province). This study also sought to determine sociodemographic and environmental factors associated with malaria.

Findings showed that respondents from households with lower monthly income, low literacy and those who reported the absence periodic WASH intervention in the residential area were more likely than others to report 
Table 2 Association between household sociodemographic characteristics, WASH status and household malaria by multivariate logistic regression analysis

\begin{tabular}{llllccccc}
\hline Variable & OR & SE & $\mathbf{9 5 \%} \mathbf{C l}$ & $\mathbf{P}$ & aOR & SE & $\mathbf{9 5 \% ~ C l}$ & Adjusted P \\
\hline Household size & 1.3 & 0.08 & $1.14-1.49$ & $<0.001$ & 1.43 & 0.13 & $1.18-1.73$ & $<0.001$ \\
Preventive measures (ITN vs. Other) & 0.41 & 0.15 & $0.18-0.87$ & 0.053 & 0.47 & 0.23 & $0.17-1.25$ & 0.133 \\
Periodic WASH intervention (Yes vs. no) & 1.86 & 0.23 & $0.10-1.26$ & $<0.05$ & 1.83 & 1.15 & $1.10-2.54$ & $<0.05$ \\
Water source (appropriate?: no vs. yes) & 0.48 & 0.19 & $0.22-1.07$ & 0.076 & 2.41 & 0.18 & $1.17-2.96$ & $<0.05$ \\
Monthly income (<50 USD vs. 50-700 USD) & 1.71 & 0.28 & $1.23-3.51$ & $<0.05$ & 1.68 & 0.45 & $1.46-2.36$ & $<0.05$ \\
\hline
\end{tabular}

ITN Insecticide-treated bed net, $a O R$ adjusted odds ratio, $p$ p-value, WASH water-sanitation-hygiene status, USD United States' dollar

Italic values indicate the significance of $p$-values less than 0.05

malaria. A recent study carried out among South African women also showed that low literacy and low household income were associated with a history of malaria [14]. On one hand, regarding the relationship between malaria and economic status, the disease is known to cause or deepen poverty through spending on health care and loss of income, and people living in extreme poverty such as in rural DRC are at a high risk of being infected, given the difficulty to have access to effective preventive measures and malaria care [15-17]. On the other hand, the study did not show any association between education and malaria. One possible reason could be the hyperendemic status of malaria in districts where the study was conducted, given the proximity to river and numerous stagnant water spots during the rainy season, with a huge mosquito population as a consequence. Future studies will investigate the contribution of these factors in malaria prevalence in DRC.

Access to health care services is considered crucial to improving the health of populations [7]. In several developing countries, $\mathrm{PHC}$ has rendered malaria diagnosis and care affordable even to people living in remote areas in Africa [18]. However, in DRC, a country with high rate of unemployment, inexistence of national health insurance system and where the majority of the population live in extreme poverty, malaria diagnosis and care are not affordable to many households. In fact, for almost three decades, the Congolese government and most private companies pay to employees monthly allowances different from salaries decided by the country's law. For instance, in the health sector, the monthly income for a nurse approximately 101 USD, and 122 USD for a laboratory technician [19]. With the current Congo crises, the country's economy has worsen with a record currency debasement and hyperinflation; some public servants' monthly allowance is actually less than 50 USD. According to USAID, large segments of the Congolese population currently live below the poverty line threshold of 1.25 USD per day [20].
This study showed that $24.1 \%$ of malaria-affected respondents did not get treated at a health setting when they were infected, even when the diagnosis was made in a medical setting. In fact, self-medication is quite a common behavior in DRC for poor households, as for some other countries of the sub-Saharan region [21, 22]. When an individual is diagnosed with malaria, but cannot afford the treatment cost, he or she may purchase malaria drug a local a drugstore, sometimes ignoring the possible consequences of this practice.

This study showed higher frequency of malaria in households from the rural site in the previous 12 monthperiod, as compared with urban ones. Similar trends were found in other reports from SSA countries. For example, a study conducted in the northern Zambian district of Nchelenge between 2012 and 2015 in 2486 individuals from 742 households showed a malaria rapid diagnostic test (RDT) positivity that reached 52\% in 2015 [23]. Another study by Ajani and Ashigidigbi [24] conducted in a Nigerian rural district found that low level of awareness and large household size were among the major risk factors for malaria in rural households.

Furthermore, vector control through ITN and IRS is one of the measures that are reported to be effective as they reduce mosquito population and bites and, in DRC, the use of ITN is the main preventive measure that is promoted, given that not all households can afford the cost of IRS and mosquito repelling skin lotion. This study showed that the majority of households used ITN. Although a relatively higher proportion of household using ITN were found to have lower malaria frequency as compared with the group of those who did not use ITN, no association was observed between ITN use and household malaria.

There are previous studies that reported association between ITN use and malaria incidence $[25,26]$. This fact can be explained first by the emergence of insecticideresistant Anopheles species, which is currently considered one of the major challenges facing national malaria control programmes in Africa [27]. The same is true for 
DRC. For instance, a nationwide study conducted in several Congolese provinces showed a number of malaria vector species that were resistant to common insecticides used to treat bed nets [28]. In another study conducted in Kinshasa province where is located one of the sites of the present study, Riveron and colleagues found high resistance of Anopheles gambiae and Anopheles funestus to two commonly used insecticides, namely dichlorodiphenyltrichloroethane (DDT) and permethrin. This resistance phenomenon is worrisome as it leads to a reduced insecticidal effect of bed nets against Anopheles [29].

Additionally, in malaria hyperendemic zones such as Kinshasa and Kongo central provinces in DRC, the high mosquito population density, mainly due to poor WASH, contribute to increased malaria rates as people are exposed to mosquito bites almost anywhere before bedtime. A work by De Silva and Marshall [30] has shown that in the southern African countries, including DRC, the presence of mosquito breeding sites such as water puddles and seepages in homes and public areas was associated with malaria. This fact is in line with the findings of this study which suggest that poor WASH, particularly the use of inappropriate water source (which contribute to create water puddles) and latrines, and the absence of periodic sanitation intervention might have influenced household malaria frequency in our study sites.

The cross-sectional design is one of the limitations of this study, but nonetheless results may reflect the reality of the two study sites. Additionally, in this study, respondents had to report on malaria status in the previous 12-month period that preceded the survey, which may be subject to recall bias. Another fact is that, during hot weather in tropical regions, some individuals do not like to use ITN to protect themselves against mosquito bites. A study conducted by Guerra and colleagues [31] showed that, of the $40 \%$ of participants owning ITN in the Guinean village of Miyobo, only 36\% ITN users has been consistently using this preventive measure. However, in this study, consistency in ITN use was not investigated.

\section{Conclusion}

The present pilot study showed high malaria incidence in Congolese households in a context of extreme poverty, and household size, WASH status and rural site were revealed to be major factors associated with household malaria. To scale up malaria programme in DRC, antivector measures such as ITN and IRS should be made accessible to the populations at risk [32], along with the implementation of periodic WASH interventions in residential areas. This might possibly lead to an efficient control of malaria.

\section{Abbreviations}

ACT: artemisinin-based combination therapy; DDT: dichlorodiphenyltrichloroethane; DRC: Democratic Republic of Congo; IRS: indoor residual spray; ITN: insecticide-treated net; LLIN: long-lasting insecticide-treated net; MDG: millennium development goal; MIQ: malaria indicator questionnaire; PHC: primary health care; RDT: rapid diagnostic test; SDG: sustainable development goal; SSA: sub-Saharan Africa; WASH: water, sanitation and hygiene; WHO: World Health Organization.

\section{Authors' contributions}

NRN, SK, MI, RW, SMJM designed the study and contributed to its implementation, in data analysis and manuscript writing; $\mathrm{TS}, \mathrm{SI}, \mathrm{KW}, \mathrm{LN}$, ON and ABM participated in data analysis and interpretation as well as manuscript writing. All authors read and approved the final manuscript.

\section{Author details}

${ }^{1}$ School of Medicine and Graduate School of Public Health, International University of Health and Welfare, Narita, Japan. ${ }^{2}$ Graduate School of Nursing, University of Kochi, Kochi, Japan. ${ }^{3}$ Western Sydney University, Perth, Australia. ${ }^{4}$ Faculty of Medicine, University of Kinshasa, Kinshasa, Democratic Republic of Congo. ${ }^{5}$ Department of Environmental Medicine, Kochi University Medical School, Nankoku, Japan. ${ }^{6}$ National Center for Global Health and Medicine, Tokyo, Japan. ${ }^{7}$ Department of Public Health, University of Kamina, Kamina, Democratic Republic of the Congo. ${ }^{8}$ School of Public Health, University of Lubumbashi, Lubumbashi, Democratic Republic of the Congo. ${ }^{9}$ Tokyo Women's Medical University, Tokyo, Japan.

\section{Acknowledgements}

The authors thank the staff of 'Congo Heiwa Mura, and William Booth University, Kinshasa, for their support to this project.

\section{Competing interests}

The authors declare that they have no competing interests.

\section{Availability of data}

All data generated are included in this paper. Original data files are kept in research repository of the University of Kochi, Japan, where the research project was initiated.

\section{Consent to publish}

Not applicable.

\section{Ethics approval and consent to participate}

This study was approved by the ethics committee of the School of Public Health, University of Lubumbashi, and the territorial health authorities of Kasangulu and Mbanza-Ngungu territory in Kongo Central province, Democratic Republic of Congo. Each responder provided written and signed informed consent form.

\section{Funding source}

The 'Congo Malaria and Communicable Diseases Project' is supported by the Grant-in-aid for Scientific research (KAKENHI No 17H04675) Japan Society for the Promotion of Science (JSPS) 2016 (for malaria and communicable diseases project). The funders are not involved in any activity related to this study project.

\section{Publisher's Note}

Springer Nature remains neutral with regard to jurisdictional claims in published maps and institutional affiliations.

Received: 2 December 2018 Accepted: 14 February 2019

Published online: 26 February 2019 


\section{References}

1. WHO. World Malaria report 2016. Geneva: World Health Organization. https://www.who.int/malaria/publications/world-malaria-report-2016/ report/en/. Accessed 27 Jan 2019

2. United Nations. The millennium development goals report 2015. http:// www.un.org/millenniumgoals/2015_MDG_Report/pdf/MDG\%20201 5\%20rev\%20(July\%201).pdf. Accessed 27 Jan 2019.

3. Naidoo I, Roper C. Drug resistance maps to guide intermittent preventive treatment of malaria in African infants. Parasitology. 2011;138:1469-79.

4. Nature News. Researchers hunt down fake drugs. http://www.natur e.com/news/2008/080211/full/news.2008.568.html. Accessed 22 Sept 2018

5. Walker EJ, Peterson GM, Grech J, Paragalli E, Thomas J. Are we doing enough to prevent poor-quality antimalarial medicines in the developing world? BMC Public Health. 2018;18:630.

6. Cohee $L$, Laufer M. Tackling malaria transmission in sub-Saharan Africa Lancet Glob Health. 2018;6:e598-9.

7. Kizito J, Kayendeke M, Nabirye C, Staedke SG, Chandler CIR. Improving access to health care for malaria in Africa: a review of literature on what attracts patients. Malar J. 2012:11:55

8. Jeffery GM. The role of chemotherapy in malaria control through primary health care: constraints and future prospects. Bull World Health Organ. 1984;62(Suppl 1):49-53.

9. O'Meara WP, Noor A, Gatakaa H, Tsofa B, McKenzie FE, Marsh K. The impact of primary health care on malaria morbidity-defining access by disease burden. Trop Med Int Health. 2009;14:29-35.

10. Mwandagalirwa MK, Levitz I, Thwai KL, Parr JB, Goel V, Janko M, et al. Individual and household characteristics of persons with Plasmodium falciparum malaria in sites with varying endemicities in Kinshasa province, Democratic Republic of the Congo. Malar J. 2017;16:456.

11. Chiribagula VB, Mboni HM, Amuri SB, Kamulete GS, Byanga J, Duez P. Prevalence of self-medication among students 18 to 35 years residing in Campus Kasapa of Lubumbashi University. Pan Afr Med J. 2015;21:107 (in French).

12. Musoke D, Miiro G, Ndejjo R, Karani G, Morris K, Kasasa S, et al. Malaria prevention practices and associated environmental risk factors in a rural community in Wakiso district. Uganda. PLoS One. 2018;13:e0205210

13. Wumba R, Ngatu NR, Luzitu SN. Malaria: an environmental health issue with tremendous socioeconomic impact on households in Democratic Republic of Congo. In: Sherman W, editor. Handbook on Africa: challenges and issues of the 21st century. New York: Nova Science Publishers; 2016. p. 211-26

14. Mutegeki E, Chimbari MJ, Mukaratirwa S. Assessment of individual and household malaria risk factors among women in a South African village. Acta Med. 2017;175:71-7.

15. World Bank. Poverty reduction and the health sector. World Bank's poverty reduction strategy source book. Washington DC: World Bank; 2001.

16. Worrall E, Basu S, Hanson K. Is malaria a disease of poverty? A review of the literature. Trop Med Int Health. 2005:10:1047-59.

17. Chuma JM, Thiede M, Molyneux CS. Rethinking the economic costs of malaria at the household level: evidence from applying a new analytical framework in rural Kenya. Malar J. 2006;5:76.

18. Littrell M, Gatakaa H, Evance I, Poyer S, Njogu J, Solomon T, et al. Monitoring fever treatment behaviour and equitable access to effective medicines in the context of initiatives to improve ACT access: baseline results and implications for programming in six African countries. Malar J. 2011;10:327.

19. Bertone MP, Lurton G, Mutombo PB. Investigating the remuneration of health workers in the DR Congo: implications for the health workforce and the health system in a fragile setting. Health Policy Plan. 2016:31:1143-51.

20. US Agency for International Development (USAID). A short dialogue on extreme poverty in Democratic Republic of Congo. https://www.usaid gov/frontiers/2014/publication/section-1-short-dialogue-extreme-pover ty-democratic-republic-congo. Accessed 27 Jan 2019.

21. Chipwaza B, Mugasa JP, Mayumana I, Amuri M, Makungu C, Gwakisa PS. Self-medication with anti-malarials is a common practice in rural communities of Kilosa district in Tanzania despite the reported decline of malaria. Malar J. 2014;13:252.

22. Kamitalu RK, Aloni MN. High school students are a target group for fight against self-medication wit antimalarial drugs: a pilot study in University of Kinshasa, Democratic Republic of Congo. J Trop Med. 2016;2016:6438639.

23. Pinchoff J, Chaponda M, Shields TM, Sichivula J, Muleba M, Mulenga M, et al. Individual and household level risk factors associated with malaria in Nchelenge district, a region with perennial transmission: a serial crosssectional study from 2012 to 2015. PLoS ONE. 2016;11:e0156717.

24. Ajani OIY, Ashagidigbi WM. Effect of malaria on rural households' farm income in Oyo state, Nigeria. Afr J Biomed Res. 2008;11:259-66.

25. Plucinski MM, Chicuecue S, Macete E, Colborn J, Yoon SS, Kachur SP, et al. Evaluation of a universal coverage bed net distribution campaign in four districts in Sofala Province, Mozambique. Malar J. 2014;13:427.

26. Kesteman T, Randrianarivelojosia M, Piola P, Rogier C. Post-deployment effectiveness of malaria control interventions on Plasmodium infections in Madagascar: a comprehensive phase IV assessment. Malar J. 2016;15:322.

27. Ondeto JM, Nyundo C, Kamau L, Muriu SM, Mwangangi JM, Njagi K, et al. Current status of insecticide resistance among malaria vectors in Kenya. Parasit Vectors. 2017;10:429

28. Watsenga F, Manzambi EZ, Lunkula A, Mulumbu R, Mampangulu T, Lobo $\mathrm{N}$, et al. Nationwide insecticide resistance status and biting behaviour of malaria vector species in the Democratic Republic of Congo. Malar J. 2018;17:129.

29. Riveron JM, Watsenga F, Irving H, Irish SR, Wondji CS. High Plasmodium infection rates and reduced bed net efficacy in multiple insecticideresistant malaria vectors in Kinshasa, Democratic Republic of Congo. J Infect Dis. 2018;217:320-8.

30. De Silva PM, Marshall JM. Factors contributing to urban malaria transmission in sub-Saharan Africa: a systematic review. J Trop Med. 2012;2012:819563.

31. Guerra M, de Sousa B, Ndong-Mabale N, Berzosa P, Arez AP. Malaria determining risk factors at the household level in two rural villages of mainland Equatorial Guinea. Malar J. 2018;17:203.

32. Maitland K. Severe malaria in African children: the need for continuing investment. N Engl J Med. 2016:375:2416-7.

Ready to submit your research? Choose BMC and benefit from

- fast, convenient online submission

- thorough peer review by experienced researchers in your field

- rapid publication on acceptance

- support for research data, including large and complex data types

- gold Open Access which fosters wider collaboration and increased citations

- maximum visibility for your research: over 100M website views per year

At $\mathrm{BMC}$, research is always in progress.

Learn more biomedcentral.com/submissions 